\title{
DA NORMA AO RISCO: TRANSFORMAÇÕES NA PRODUÇÃO DE SUBJETIVIDADES CONTEMPORÂNEAS
}

\author{
Thiago Drumond Moraes* \\ Maria Lívia do Nascimento
}

\begin{abstract}
RESUMO. O objetivo do presente artigo é demonstrar, com base na premissa foucaultiana de que a resistência é sempre primeira, algumas transformações que se deram com o movimento social de recusa à sociedade disciplinar a partir de profundas mudanças nos processos de produção de subjetividade e de controle sobre os corpos e os comportamentos. As transformações em análise dizem respeito à passagem de uma sociedade fundada na normatização dos sujeitos para uma sociedade de controle dos riscos do cotidiano, o que permitiu, em grande parte, uma revitalização da capacidade de comando social do capitalismo sobre as pessoas. Resulta dessa análise, portanto, a apreensão de alguns mecanismos de poder que vêm sendo impostos e naturalizados hoje em dia e que subjetividades são produzidas por eles.
\end{abstract}

Palavras-chaves: produção de subjetividade, sociedade de controle, risco.

\section{FROM NORM TO RISK: TRANSFORMATION IN THE CONTEMPORARY PRODUCTION OF SUBJECTIVITIES}

\begin{abstract}
The following article is based on the Foucautian premise that resistance is always the first step. The article also functions as a barometer of the transformations stemming from the social movements that rejected the disciplinarian society. These transformations include: changes on production of subjectivity and changes in the control of bodily behavior. These transformations will then chart the transition from a society based on the normatization of the subjects to that of a society which controls the risks of the everyday life. Secondly, the article will show this transition leading to the revitalization for the capacity of social command of capitalism over the people. Finally, it will reveal the institutionalization of some power mechanisms which have been imposed and naturalized nowadays, and to the subjectivities which they have in sequentially produced.
\end{abstract}

Key words: production of subjectivity, control society, risk.

No livro Vigiar e Punir, Foucault (1987) põe em prática "novas" metodologias de abordagem das questões do poder, recusando as clássicas investidas da filosofia e da ciência política que apoiavam a discussão sobre o poder em torno da esfera do Estado ou de qualquer outra organização centralizada. Para Foucault, a problemática do poder deveria circular não tanto em torno da questão da legitimidade do direito (e do poder central), da sujeição e da obediência dos indivíduos à soberania estatal - fazendo aparecer no lugar da soberania e da obediência o problema da dominação e da sujeição - mas em observar que técnicas, mecanismos e aparelhos institucionais de controle e dominação sobre os corpos e os indivíduos, e portanto produtores de subjetividade, garantiam a legitimidade dessa configuração social. A discussão sobre as diversas técnicas de controle e dominação social, por outro lado, não deveria ser apreendida como um reflexo causal de um determinado modo de produção - embora estivesse intrinsecamente ligada a ele.

A análise do poder deveria, pois, descolar-se da centralidade política e penetrar nos meandros técnicos e capilares de sua sustentação. Além disso, para Foucault, o poder, muito mais que repressivo, é produtivo. Cria, a partir de seu funcionamento, realidades, sujeições, sujeitos e objetos. Isso significa que, mesmo que pela intervenção proibitiva, o efeito

\footnotetext{
* Aluno do Mestrado em Psicologia da Universidade Federal Fluminense. Agência de fomento FAPERJ.

Endereço para correspondência: Rua 22 de Abril, 679, Manguinhos, 29173-041, Serra-ES E-mail: thiago_drumond@hotmail.com

\# Professora Doutora do Programa de Mestrado em Psicologia da Universidade Federal Fluminense.
} 
principal e o interesse de quem exerce o poder sobre outrem são de que sua ação interfira no comportamento, na ação do outro. Quem exerce o poder pretende fazer o outro agir, pensar, sentir, analisar e se posicionar diante das coisas de acordo com seu interesse. Nas palavras de Foucault,

Aquilo que se define como uma relação de poder é um modo de ação que não age direta e imediatamente sobre os outros, mas que age sobre sua própria ação. Uma ação sobre a ação, sobre ações eventuais, ou atuais, futuras ou presentes (Foucault, 1995, p. 243).

É a partir dessas premissas que, para Foucault, os homens se tornam sujeitos, percebem e, principalmente, empreendem um certo modo de vida e de mundo. Apreender essas relações, por outro lado, nos leva a visualizar a importância das microfactualidades que se dão nas práticas do exercício do poder cotidianamente - até porque só há poder em exercício, em prática, em ação. Tanto o mundo quanto os sujeitos são forjados nessas práticas, não havendo, pois, nada pronto, dado, qualquer materialidade "natural"1.

Não obstante, o que é ainda mais importante para Foucault é que nessa atualização cotidiana das práticas sociais e de exercício do poder se localizam as resistências contra estes. Relação de poder é ação sobre a ação do outro. Ou seja, é na ação que se exerce sobre alguém que se encontra um campo de resistência em permanente ação. Abre-se, pelas práticas moleculares de contrapoder, um universo ilimitado de possibilidades de se inventar a vida, no qual podem ser viabilizadas a produção de desejo, a criação de mundos e a fruição da vida. Ao se resistir, criam-se, por conseguinte, novas realidades, sujeitos e objetos - em uma palavra, subjetividades - que escapam, ou tentam escapar do controle direto de quem exerce o poder.

Do exposto extraem-se duas premissas principais: 1) a produção do mundo é sempre ação no presente; 2) essa ação, para manter os princípios naturalizados do mundo inventado, terá que lidar com sujeitos, interesses, invenções, migrações, movimentos criados ininterruptamente nos campos de luta abertos pelas resistências ao exercício de poder. Dessas premissas chegamos à seguinte conclusão: as mudanças que acontecem na história são efeitos de embates entre um esforço cristalizado de manutenção de determinado mundo previamente inventado - um poder constituído, operando através de ações e normas instituídas - e

Sobre o assunto ver Foucault (1995) outras forças sociais que resistem a esses mundos, e que acabam criando os seus próprios mundos, com subjetividades específicas, tecnologias novas, discursos outros e desejos diferentes - um poder constituinte produzindo ações, modelos, formas de ser instituintes . Ou seja, ao buscar atualizar a força de imposição das relações de poder, quem exerce o poder vai ter que reinventar sempre novos mecanismos de controle, buscando incorporar, sob o seu comando, as novas formas de ser inventadas pelas resistências que se dão contra esse poder. As formas, técnicas e mecanismos de aplicação do poder vão variando na história em função das novas formas e subjetividades que as resistências vão criando ao longo do tempo.

\section{A NORMATIZAÇÃO DA SOCIEDADE OPERADA PELO PODER DISCIPLINAR}

O poder disciplinar emerge por volta dos séculos XVII e XVIII, concomitante à revolução social que inaugura a modernidade. É um modo de organização social que tem como linhas de apoio a invenção de um mundo calcado no pensamento/discurso do Iluminismo, a introdução do capitalismo fabril e a organização e gestão do Estado pela classe burguesa. Seu sustentáculo principal é a maneira bastante específica de conceber e produzir os corpos e as subjetividades.

Diferentemente do poder soberano ${ }^{2}$, o poder disciplinar tem como princípio a formação de corpos úteis, bem esquadrinhados, domesticados, treinados e preparados para a produção e o futuro. Isso se dá pelo controle e vigilância das atividades do corpo, pela aplicação de um rigoroso controle do horário, pela investigação do tempo da ação, da observação dos mínimos procedimentos.. As instituições disciplinares permitem, pois, o desenvolvimento de vários saberes sobre os corpos e sobre os indivíduos, descrevendo os padrões desejados de funcionamento - a partir da análise comparativa dos corpos expostos nos seus interiores - e estabelecendo um modelo a seguir. É assim que o poder disciplinar inaugura a sociedade da norma, do normal, do padrão, do comportamento que opera em função do modelo - um controle que se dá e se interioriza nas pessoas em função daquilo que elas deveriam ser. Nas escolas e nas fábricas, nos manicômios, o tempo ideal, as atitudes "normais", os comportamentos-padrões, as "boas" performances serão observados, comparados, medidos e descritos, servindo de parâmetro de classificação entre as pessoas.

\footnotetext{
2 Sobre o poder soberano ver Foucault $(1987,1999)$.
} 
Cria-se, assim, nessa eclosão dos saberes racionais sobre o mundo e sobre as pessoas, o Homem enquanto objeto de saber. Ora, se o conceito de Homem é criado pelos saberes disparados pelo poder disciplinar, e se este poder/saber opera por meio de modelos e normas, um efeito fundamental das sociedades disciplinares é que por suas instituições a categoria de "homem civilizado" torna-se o modelo de homem do mundo. Este modelo é construído em cima da figura tradicional do homem-branco-macho-adulto. Todos os que não se enquadram nesse modelo devem, em última análise, ser desqualificados, tomados com suspeição, observados e vigiados com o máximo de atenção. Esse modelo e suas normas correlatas ultrapassam as fronteiras das instituições e começam a se tornar objeto de lei. Inauguram-se, assim, as sociedades de normatização, nas quais os valores da norma são tornados referenciais para os valores da moral, da justiça, do trabalho, da penalidade, enfim, para toda a sociedade.

O poder disciplinar, portanto, faz valer o poder de análise, investindo no corpo não como força natural, mas como potência à individuação e formatação a um modelo útil e obediente. O corpo (humano ou social) é deixado de ser massa compacta, e torna-se uma heterogeneidade (de gestos ou indivíduos), através de dispositivos analíticos e combinatórios.

A partir desse diagrama de poder, a generalização da produção industrial se torna possível e o custo do treinamento dos corpos quase inexistente, haja vista que outras instituições já o empreenderam. Agora, ao mais-poder empregado pelas instituições disciplinares corresponde uma mais-produção do social e uma mais-valia ao capital. A generalização da disciplina se torna possível, viável e necessária.

Em suma, podemos observar que a disciplina é uma técnica de poder que se exerce ininterruptamente sobre os corpos das pessoas, individualizando-os, intervindo diretamente no treinamento e uso de suas forças. Assim, cria-se o indivíduo inserido em um espaço já previamente recortado e analisado, incidindo sobre ele experiências, utilizações e controle do seu tempo, e impondo-se lhe uma vigilância incisiva e ininterrupta. Portanto, é com uma determinada experiência do espaço e do tempo que se afirma, em parte, a disciplina.

\section{A SOCIEDADE DE NORMATIZAÇÃO POSTA EM QUESTÃO}

É claro que o papel exercido pelas normas foi sendo questionado incessantemente ao longo da aplicação do poder disciplinar. O movimento operário em ascensão durante o século XIX foi, de uma forma indireta, produto dessa imposição normatizadora, que tornava o corpo mero sustentáculo energético de extração da exploração capitalista. No entanto, esses movimentos, reforçados com os ganhos de produtividade disparados pelo taylorismo, não conseguiram forças suficientes para construir outros modelos de sociedade que escapassem do princípio disciplinar que vinha sendo imposto com força cada vez maior nas sociedades centrais.

As sociedades disciplinares atingiram o seu auge após a $2^{\mathrm{a}}$ Guerra Mundial, quando as instituições disciplinares se espalharam por virtualmente todos os países do globo, se tornando os principais instrumentos de controle social e da modernização. Em todo o mundo a disciplina passa a ser o modelo de funcionamento geral da sociedade e a produção de indivíduos em série se torna o padrão e a norma de produção de subjetividade.

Essa generalização mundial das disciplinas permitiu, em contrapartida, que as resistências contra ela também se tornassem mundiais: movimentos hippies de recusa à cultura de massa eclodem simultaneamente em quase todos os países ocidentais; movimentos de expressão e de liberdade, por outro lado, se espalham pelos países socialistas; as revoluções religiosas no Irã e o crescimento do fundamentalismo religioso no Oriente Médio se manifestam como recusa da modernização ocidental; surgem os movimentos raciais nos Estados Unidos e na África do Sul; eclodem reivindicações de liberdade sexual nos países centrais e movimentos de reforma psiquiátrica e de liberdade pedagógica. São todos movimentos disparados, direta ou indiretamente, em função do enquadramento das identidades - o louco, o homossexual, a mulher, o jovem, o negro, o muçulmano - em escalas de normalidade/anormalidade hierarquizantes, despotencializadoras, racistas, patologizantes.

As recusas a esse modelo de sociedade foram entoadas por mil vozes, em mil tons e mil intensidades, e as subjetividades produzidas em escalas mundiais pelas forças de resistência puseram em cheque as instituições disciplinares. A recusa ao trabalho, à família, à escola, ao consumo, à lei, à sociedade, à repressão e à falta de liberdade de expressão se transforma em uma ameaça ao diagrama de força do poder disciplinar. A multidão ${ }^{3}$ põe $o$ modelo de controle social disciplinar em crise.

O conceito de multidão trabalhado por autores de tradição operaísta italiana atinge as novas luta e os novos sujeitos que vêm emergindo dentro das atuais transformações do 
Apesar da força de repressão - greves contidas à força, os movimentos de contracultura igualmente, intervenções armadas do Estado em vários países socialistas e inúmeros golpes militares ou guerra civil nos países periféricos - a multidão não sustenta mais um mundo completamente disciplinar como outrora. Muitas das subjetividades criadas nos últimos trinta anos simplesmente não se enquadram mais em instituições insulares. O comando social que se produziu com e pela sociedade disciplinar teve que se recompor para continuar a manter o controle social. Os primeiros sinais de um novo modo de organização social se fazem presentes.

Como argumenta Deleuze (1992), foi no movimento de recusa ao poder disciplinar que transformações importantes ocorreram nas instituições disciplinares. A multidão recusa as normas das instituições, forçando uma permeabilização de seus muros. As identidades fixas e patologizadas são recusadas e os movimentos de reforma abrangem o Estado, a família, a escola, os hospitais, o trabalho e as cidades. O controle social já não pode operar apenas pela norma. É importante a criação de outros mecanismos eficazes de comando, que consigam ser eficientes, econômicos e apropriados ao movimento de transformação imposto pela multidão.

Foucault, em trabalhos posteriores ao livro Vigiar e punir (1987), onde o problema da sociedade disciplinar foi primeiramente levantado, argumenta que paralelamente ao poder disciplinar, outros mecanismos de produção de subjetividade e de controle social foram sendo inventados, tendo como objeto de aplicação de poder o corpo-espécie.

capital. Esses autores opõem multidão ao conceito de proletariado, afirmando que este não é mais o sujeito por excelência da resistência ao capitalismo. De fato, a multidão não seria bem um sujeito da resistência, mas uma unidade de luta composta pela fragmentação da classe, pela diversificação dos atores sociais e pela afirmação da diferença, emergida das lutas contra a sociedade disciplinar que desembocaram nos atuais movimentos contra a globalização e o capitalismo financeiro. Hardt e Negri (2002) estabelecem uma diferença entre o conceito de multidão e o de povo e população. A produção dos dois últimos conceitos está atrelada a um longo processo de subjugação das forças sociais sob um comando calcado na soberania e transcendência. Por multidão, por outro lado, os autores entendem a multiplicidade das relações sociais calcadas na heterogeneização, na criação e na força da imanência. Assim, com a criação do Estado-Nação e pela incorporação da disciplina, o que se pretende é "transformar a multidão em povo" (2001:120). Constata-se, como argumenta Lazzarato (2001), que "a população, objeto da biopolítica, se metamorfoseou em multidão, sujeito de uma política a vir" (p.162). Ver também Cocco e Hopstein, (2002).
Segundo Foucault (1979), o surgimento do problema da vida da população entra em cena, na sociedade européia, em função da problemática do governo e da relação entre Estados ${ }^{4}$. As instituições, criadas com o intuito de controlar, conhecer e melhorar a qualidade de vida da população, visavam a regular os processos de vida do povo, acompanhado-a em seus mínimos detalhes, investigando hábitos e comportamentos e estipulando campanhas para que um certo modo de viver pudesse ser empreendido pela população.

Através desses mecanismos a vida foi completamente assumida pelo poder. Não se tratava mais de cuidar apenas do corpo-indivíduo, fortalecendo-o enquanto instrumento essencial de extração de energia e mais-valia. A sociedade enquanto povo, suas características, suas regularidades e estatísticas foram transformadas em objeto de estudo e análise. As técnicas de investigação e controle da população-espécie foram se tornando cada vez mais centrais ao longo do século XIX e, principalmente, do século XX. Quando, nas últimas décadas, os movimentos de contestação à sociedade de normatização vieram à tona, abriu-se espaço para que os mecanismos biopolíticos de controle da população fossem sendo cada vez mais utilizados. Isso implicou um problema central enfrentado pela multidão. Se por um lado, ao se confrontar com a disciplina e produzir subjetividades, a multidão potencializava a força da vida e da criação na sociedade ${ }^{5}$, por outro, a sociedade de controle aprendeu a extrair comando e energia e a explorar justamente essa produção incessante da vida. A multidão produz, agora mais que nunca, desejo e vida, mas o poder, o comando, aprendeu a controlálos.

\footnotetext{
Sobre o assunto ver Foucault $(1979,1999)$.

5 É sempre bom lembrarmos que a possibilidade de liberdade no mundo é atualmente vislumbrada de maneira jamais pensada na história prévia. Chegamos, com o advento da globalização, àpossibilidade de concretizar um evento jamais sonhado outrora: nos tornarmos cidadãos do mundo. $\mathrm{O}$ mundo se encontra em real possibilidade tecnológica e produtiva para uma abertura social na qual a liberdade seja imediatamente produção, já que a criação da multidão foi assumida pelos mecanismos de produção e as possibilidades de transformação social já não são vistas como heresia. Além disso, a multidão é produtiva por si mesma e não depende mais de mecanismos exteriores e transcendentes - o Estado-Nação, a industria capitalista ou o mercado regulador - para produzir o seu mundo, criando a partir dos encontros que se dão na própria vida. $\mathrm{O}$ problema é que a globalização tem sido operada muito mais pelo capital que pelas forças da multidão, dando origem ao aumento da concentração de riqueza e da exploração das pessoas e da vida.
} 
É nessa interseção entre a vida enquanto liberdade e a vida enquanto fonte de controle e de exploração que a normatização social vai sendo questionada por parte da multidão e revista por parte das técnicas de poder. A multidão cria, ininterruptamente, subjetividade, pela qual irá desenvolver a produção do mundo e tornar a sua vida cheia de desejo e liberdade. Todavia, a sociedade de controle faz operar uma série de estratégias através das quais se utiliza provisória e parcialmente dessas subjetividades criadas pela multidão, transformando-as em imagens/espelhos identitários que devem atrair o consumo e o comportamento das pessoas. Diferentes modelos são criados a partir das figuras fornecidas pela multidão, trabalhando-as para que sejam transformadas, estratégica e lucrativamente, em imagens de consumo, identificação, imitação e referência.

Um dos principais instrumentos de operação dessa transformação é, de maneira geral, encabeçada pela mídia. Se, talvez, não seja de todo correto afirmar que o papel das propagandas, das telenovelas, telejornais e revistas circule em torno da tarefa de forjar verdades, certamente se trata de um mecanismo muito bem utilizado pelas redes de poder através do qual as subjetividades inventadas pela multidão são trabalhadas e transformadas em objeto de consumo e de identificação. Dessa forma, são técnicas de poder que conseguem efetivar o comando social, interferindo diretamente no comportamento das pessoas, nos seus afetos, ansiedades, prazeres e necessidades. São, pois, mecanismos de poder que não limitam, proíbem ou distribuem em hierarquias rígidas e patologizantes - ou, pelo menos, essa distribuição não é tão essencialista quanto o processo de normatização; elas agem de maneira diferente: funcionam por sedução, interesse, curiosidade, através da lógica do prazer incessante e incontrolável do consumo e da aquisição. Até podemos dizer, é verdade, que tais técnicas resultem em imagens mais ou menos estigmatizantes - é só lembrar as clássicas figuras das novelas televisivas -, dualizantes às vezes, mas certamente individualizantes. Não se trata, entretanto, de figuras imutáveis, fundamentalistas, fixas e previamente dadas. O consumo não suporta lidar com identidades fixas. A crise dos anos 70 mostrou bem isso, quando a redução do consumo de massa forçou a revisão imediata de todo o fundamento produtivo desenvolvido pelo modo de produção fordista.

\section{DA PRODUÇÃO AO CONSUMO: TRANSFORMAÇÕES DO CAPITALISMO CONTEMPORÂNEO}

Mas como operam essas técnicas? A partir de quais fundamentos elas se tornam viáveis? Quais os seus princípios econômicos e sociais? Essas perguntas só podem ser compreendidas se observarmos as transformações nos sistemas de produção do capitalismo ${ }^{6}$. A resistência em massa da multidão em relação às normas exigiu mudanças que impedissem o colapso do sistema capitalista. O modelo de produção fordista, que se sustenta em uma grande burocracia na planificação da produção e num intenso e profundo sistema de hierarquia, entra em crise generalizada a partir da década de 70. Os efeitos negativos do modelo surgem na forma de imensos desperdícios, grande absenteísmo, falta de investimento subjetivo no trabalho e de uma grande concentração de operários, facilitando a organização de greves e de movimentos de massa. Tudo isso torna as fábricas fordistas pouco maleáveis, impossibilitando mudanças em face das transformações cada vez mais dinâmicas do mundo.

Uma janela de oportunidades se abria no lado oposto ao Ocidente: o sistema de produção inventado nas fábricas de automóveis japonesas resultou em uma grande vantagem competitiva dos seus produtos. Por esse sistema, a produção estava vinculada diretamente ao fluxo do consumo e as indústrias conseguiam se adaptar imediatamente aos interesses dos consumidores, transformando-se em um mecanismo de produção adequado aos gostos variáveis das pessoas. Por outro lado, nos países ocidentais, a fuga de trabalhadores das grandes fábricas - principalmente trabalhadores qualificados - permitiu que parte das tarefas das indústrias viesse a ser realizada por pequenas empresas de serviço que desenvolviam suas atividades fora do controle estrito e imediato da grande indústria, tornando a sua capacidade de resposta de produção cada vez mais rápida e flexível ${ }^{7}$.

\footnotetext{
${ }^{6} \mathrm{Na}$ presente discussão diferenciamos o conceito de modo de produção capitalista - que se refere ao modelo central de acumulação baseado no princípio da propriedade privada, do dinheiro e da exploração da mão-de-obra dos nãoproprietários dos meios de produção - dos sistemas de produção que se dão dentro desse modo de produção. Assim, a hegemonia de uma certa metodologia da produção, de um determinado modo de gerir a força de trabalho, de um certo mecanismo de regular a relação capital X trabalho, dá origem a sistemas de produção dominantes em determinadas épocas: manufaturas, como o fordismo, pós-fordismo. Estes sistemas produzem subjetividades e relações de poder específicas de cada época mas não invalidam o conceito central de modo de produção e acumulação capitalista. Ou seja, existem vários sistemas de produção no modo de produção e acumulação capitalista.

7 Sobre o assunto ver Harvey (1992) e Piore e Sabel (1984).
} 
Assim, tanto o sucesso das fábricas japonesas, que operavam pelo sistema de produção just-in-time ${ }^{8}$, quanto a crescente flexibilidade nos contratos das empresas com os fornecedores de serviços, implicaram em uma transformação na esfera do trabalho, do sistema produtivo e do sistema financeiro. A imagem do trabalhador ideal já não seria mais aquela de especialista do detalhe, presente nas fábricas tayloristas, o trabalhador disciplinado. Os perfis passariam a ser múltiplos, variáveis, transformáveis, enfim, flexíveis. O que se espera é que sejam capazes de operar transformações e que possam se esforçar para acompanhar o fluxo incessante de produção da multidão. A vida das empresas depende desse esforço, já que elas só sobrevivem se conseguem associar-se às transformações impostas pelas pessoas, pela vida, e se logram utilizar esses recursos para extração de lucro e riqueza.

O sistema produtivo fordista foi sendo substituído pelo modelo de produção pós-fordista ${ }^{9}$, implicando em transformações imensas na economia política mundial, principalmente na medida em que as formas privilegiadas de obtenção de lucro e de ganância do capitalismo não se dão mais pela extração do lucro garantido através do controle do tempo de trabalho, pela exploração de mais-valia e pelo controle dos mercados. Essa transformação não foi desencadeada apenas pela mecanização e robotização das fábricas, mas também pelas transformações na própria estrutura

8 O modo de produção just-in-time, primeiramente empregado na fábrica automobilística japonesa Toyota, o qual rendeu seu nome ao sistema produtivo toyotista, se contrapõe ao taylorismo. Caracteriza-se por ser um modelo produtivo no qual o comando de produção é disparado pelo ritmo do consumo. Assim, toda a produção é desencadeada a partir do seu consumo e/ou demanda. Esse sistema permite também que o consumidor possa escolher variações no produto que escolheu, "personalizando" o objeto de consumo de acordo com os interesses de cada um. A produção acontece, então, just-in-time, "no momento" em que se dá o consumo do produto, acompanhando as particularidades de cada demanda. Ver Harvey, (1992).

9 O modo de produção pós-fordista caracteriza o modo de produção atual, no qual à predominância do modo de produção just-in-time se adiciona a crescente importância econômica do trabalho de produção de informações, de serviços, de processos educacionais, do marketing, da informática, enfim, do trabalho intelectual e imaterial. Esse modo de produção pós-fordista é, sobretudo, um sistema produtivo pós-industrial no qual a relevância da produção se torna aspecto menos importante que a invenção de mercadorias, sistemas de signos, linguagens, sentido, afeto, modos de consumo, etc. Nesse sistema ocorre uma fragmentação do parque produtivo em direção a uma produção espalhada pelo território de determinadas regiões. Ver Cocco (2000), Lazzarato e Negri (2001). da produção, com sua horizontalização, fragmentação, territorialização, forçando o capitalismo a encontrar, no próprio consumo, a fonte privilegiada de extração de riqueza e de manutenção da ganância. Torna-se importante, nesse processo, a utilização cada vez mais crescente das novas tecnologias digitais e de informação, as quais permitem uma rápida troca de informações e uma intensificação nos fluxos de comércio e negócios entre os países. Tudo isso resultou num sistema produtivo que funciona da ponta final, o consumo, para a ponta inicial, a produção. É a multidão que puxa atrás de si toda a rede produtiva, que se espalha cada vez mais pelos territórios de certas regiões, nacionais ou globais, e não mais apenas dentro de certas indústrias e firmas.

O consumo, como dito, sobressai como figura-chave da produção. Bauman (1999) chega a afirmar que nossa sociedade deixou de ser uma sociedade de produtores e soldados para se transformar em uma sociedade de consumidores. Sem querer nos ater a esse debate, podemos dizer que com o sistema produtivo just-in-time cabe ao consumo puxar a produção, nos levando à conclusão lógica de que o consumo, em última instância, se tornou produtivo ${ }^{10}$. Dessa forma talvez não seja correto afirmarmos que estamos produzindo uma sociedade de consumo, mas uma sociedade de capitalismo reprodutivo ${ }^{11}$. Ou seja, o sistema capitalista já não produz , mas reproduz, utiliza, trabalha aquilo que a multidão, em seu movimento de vida e transformação, inventa, cria, transforma, destrói. Daí a importância da criação, da adaptação que se exige dos novos trabalhadores. Daí o interesse das empresas em se adiantarem umas em relação às outras para conseguirem se adaptar ao mercado. Daí a busca desenfreada por informações que possam dar

10 Ao designarmos a importância do consumo na teia produtiva não estamos ignorando a importância cada vez maior que vem sendo dado ao problema da circulação. De fato, para permitir que o consumo se torne produtivo é fundamental que redes de circulação - de mercadoria, valores, informações, moeda, etc. - assumam papel privilegiado nessa economia. Daí podermos afirmar que a circulação é, também, produtiva. De acordo com Marx (1996), em nossa economia, cada vez mais intensamente, consumo, troca, circulação e produção vêm se cambiando em um processo de sobrecruzamento que, em última instância, tem como efeito a produção de indivíduos.

11 Aqui não se faz relação ao conceito de reprodução marxista, conceito que se refere à divisão sexual tradicional do trabalho, na qual o trabalho produtivo (e produtor de riquezas) é privilégio dos homens, enquanto o trabalho reprodutivo (desvalorizado e não remunerado) é papel das mulheres. Trata-se, em nosso caso, da idéia de que o capitalismo reprodutivo reproduz, copia, utiliza de forma exploratória aquilo que se cria pela multidão em seu cotidiano e como um processo de trabalho vivo. 
vantagens competitivas para os negócios. Tudo para que, ao utilizar a produção da multidão, o sistema capitalista consiga reproduzir e padronizar essa produção, transformando-a em objeto de consumo.

$\mathrm{O}$ que fica na ponta da sociedade de capitalismo reprodutivo é um esforço imediato em processo, em fluxo, para se controlar o comportamento das pessoas, principalmente no que diz respeito ao consumo. Apenas uma coisa é imperativa para o sistema: que o consumo nunca cesse. Se podemos, teoricamente, supor que a produção da multidão é ilimitada, e se acreditamos que o capitalismo apreende esse processo da mesma forma, o que acaba restando ao capital é fazer com que essa produção incessante seja transformada incessantemente em objeto de consumo. Daí importa manter o consumo como ato fundamental das nossas vidas ${ }^{12}$.

Pequena pausa para podermos aqui fazer duas observações. Primeira: é bom lembrar que as redes e mecanismos de poder começaram a investir, com intensidade cada vez maior, no controle da vida e da sua produção; segunda: paralelamente, a multidão buscou cada vez mais liberdade de manifestação e controle dessa produção de vida, daí resistir tão intensamente à normatização do cotidiano. Disso resulta que a sociedade de controle coloca um dilema fundamental para a multidão: a vida é transformada tanto em objeto de produção e de resistência quanto num instrumento de intervenção e produção do poder. Esse dilema fundamental da nossa era deve estar sempre em mente, para compreendermos como o risco é operado em nossa sociedade.

\section{A OPERAÇÃO DO RISCO: PODER, POTÊNCIA E CONTROLE NA EMERGÊNCIA DE UM NOVO MUNDO}

Paulo Vaz (1999) descreve o risco como um mecanismo de poder fundamental em nossa sociedade. O autor aponta a importância que o controle do

12 Talvez seja por isso que a importância da sociedade de consumo tenha sido utilizada como análise-chave na obra de pensadores como Bauman (1999). De fato, o esforço que o capital empenha atualmente em valorizar as pessoas pelo que elas têm, é um processo que encontra suas raízes justamente na idéia de que o capital já não é o único produtor do mundo. Assim, a ética do capital atual, que se distancia para uma moralização da figura do trabalhador, em direção a uma estetização do cotidiano, não pode significar o fim dos limites, como querem os psicanalistas, e nem o fim da produção, como querem alguns sociólogos. Deve significar uma revolução fundamental no modo como a vida vai sendo inserida no processo produtivo atual. Daí a sociedade de controle, ou como afirmamos acima, sociedade de capitalismo reprodutivo, ser uma sociedade da biopolítica. consumo assume como elemento chave de manutenção das estruturas de poder do capital. O capital deve se esforçar em manter as pessoas consumindo, já que é somente delas que ele extrai suas riquezas e por elas mantém sua ganância. Esse processo é tão importante que o volume de gastos na produção de marketing vem atingindo somas consideráveis, representando um importante papel estratégico tanto na venda dos produtos quanto no papel que a propaganda exerce para os governos e Estados ${ }^{13}$. Consumir é fundamental, nada pode parar esse processo.

Todavia, a lógica do consumo, tão bem descrita por Bauman (1999), é que:

A necessária redução do tempo é melhor alcançada se os consumidores não puderem prestar atenção ou concentrar o desejo por muito tempo em qualquer objeto. Isto é, se forem impacientes, impetuosos, indóceis e, acima de tudo, facilmente instigáveis e também se facilmente perderem o interesse. A cultura da sociedade de consumo envolve, sobretudo, o esquecimento, não o aprendizado (Bauman, 1999, p. 90).

De acordo com o autor, o consumo não pode ser baseado em pessoas muito fiéis aos produtos e é fundamental que o prazer seja tão intenso quanto rápido, mas que nunca seja capaz de esgotar o desejo de mais consumo. Consumir o mais intensamente possível, em um pequeno espaço de tempo, deixando atrás de si uma segura sensação de satisfação mas, também, um imenso desejo de "quero mais...".

Por outro lado, as pessoas querem mais vida, querem expressar seus sentimentos, sentir o regozijo do desejo. A vida, na contemporaneidade, vai se tornando cada vez mais o valor supremo. As pessoas querem se sentir bem, ser felizes, viver em eterna juventude. Todos queremos viver cada vez mais e melhor. A juventude quer experimentar a vida ao máximo, os casais exploram os prazeres com intensidades cada vez maiores, conquistas de inúmeras lutas que fazem a vida humana ficar cada vez mais próxima do controle das próprias pessoas.

Um problema emerge, então, para o comando social. Como intervir naquilo que é intensamente reivindicado pelas próprias pessoas? O que fazer para se lograr intervir na ação do outro, quando é a vida em sua virtualidade e criação que se deve controlar? O capitalismo conseguiu algumas respostas.

13 Sobre o assunto e sobre o papel da mídia na produção de subjetividade ver Coimbra (2001). 
Percebemos, atualmente, um grande investimento na estética, no valor da vida, na experimentação do prazer. Por outro lado, aceitar a finitude das coisas é algo ainda muito pouco tolerado em nossa vida. A monotonia do mesmo percurso diário para o trabalho, das mesmas notícias na TV, dos mesmos papos nos bares, das mesmas pessoas nas ruas, é uma afronta à intensa busca de novidade. Viver é sinônimo de aprender, de experimentar, de inventar. A monotonia, a imobilidade, a regularidade e constância significam despotencialização da capacidade humana de se realizar. É a finitude.

É nesse cruzamento que o risco para a vida, para o movimento, para a manutenção do fluxo de criação se torna um duplo perigo: por um lado, perigo para uma multidão que não tolera os horrores da violência contra a vida ${ }^{14}$; por outro lado, a cessação da vida se transforma em um perigo para o capitalismo, já que todo o seu lucro é calcado na reprodução e utilização dessa produção da vida pela multidão ${ }^{15}$. O fim do fluxo da vida deve ser evitado a qualquer custo. Os órgãos sociais começam a se interessar pelos perigos que ameaçam a vida, a criação e a mobilidade. Lançam-se campanhas pela saúde, pelo fim dos hábitos perigosos, pelo controle da violência urbana ${ }^{16}$, pela manutenção de um prazer saudável e produtivo. Tudo que pode antecipar o fim da vida é colocado em evidência, implicando em campanhas de instituições não governamentais, órgãos estatais ou movimentos sociais, no sentido de transformar os hábitos, comportamentos e desejos considerados riscos à vida.

O problema do risco emerge assim com força total. É de tal sorte essa questão social que os sociólogos investiram abertamente na tarefa de compreendê-la, chegando alguns deles, segundo

14 A multidão não tolera mais a violência - o terrorismo imprevisível, o seqüestro-relâmpago, a insegurança pública - bem como busca lidar de modo cada vez menos tolerante com a morte e a doença, o que pode ser verificado no investimento das pessoas na manutenção de sua saúde, de seu vigor, e na busca de um envelhecimento com saúde.

15 Assim, o fim da vida é o fim do consumo, o fim da exploração do capital, enfim, seu próprio desmantelamento.

16 Não se nega, aqui, toda a problemática da violência, que inclui problemas de concentração de renda, de classes, de raças, etc. $\mathrm{O}$ que se sugere nesse texto é que, apesar dessa problemática, a mídia e as pessoas acabam produzindo subjetividades que são moralizadoras, e que o poder consegue trabalhar muito bem, num processo de simplificação das questões envolvidas no problema da violência. Por outro lado, esse medo da violência é um medo legítimo que não foi produzido, unicamente, como mecanismo de poder e de controle, mas que aparece, também, como recusa da violência contra a vida.
Layrargues (2001), a propor que estamos vivendo uma sociedade do risco. Nosso intuito não é debater a veracidade dessa afirmação, mas mostrar, mais microfisicamente, como a questão do risco é operada pelos mecanismos de poder, reforçando as estruturas de dominação capitalista e se tornando um instrumento privilegiado da sociedade de controle.

De fato, o conceito de risco enquanto importante categoria de análise sociológica tornou-se conhecido através dos estudos do sociólogo alemão Ulrich Beck. Para esse autor, estamos vivendo uma nova modernidade, em que se põem em questão e análise as antinomias da primeira modernidade, esta calcada nos princípios de uma "sociedade estatal e nacional, estruturas coletivas, pleno emprego, rápida industrialização, exploração da natureza não "visível"” (Beck, 2000). A segunda modernidade, ou também modernidade "reflexiva", se inaugura quando a humanidade se depara e se espanta com o assombroso desenvolvimento técnico-industrial em curso na sociedade e, principalmente, com a sua potencialidade imensamente destrutiva para a existência humana. Além disso, percebeu-se que esses riscos de desastre já não se reduzem a apenas uma ou outra classe social. O risco, agora, é mundial. É assim que, segundo Pires (2001), os perigos e espantos da industrialização moderna vão desembocando na sociedade do risco: uma superprodução que incapacita e esgota a natureza, o fim dos limites do tempo e do espaço dos desastres provenientes da indústria, uma complexificação nas relações de causalidade, responsabilidade e culpabilidade desses desastres que, de qualquer forma, não podem ser facilmente compensados. Somam-se a isso os perigos provenientes das novas relações econômicas, que, de forma geral, não são sempre tomadas em conta pelas decisões políticas e científicas sobre os problemas do risco.

A esses riscos mais "materiais" desencadeados pela intensa industrialização desde meados do século passado somam-se outros, de natureza mais "imaterial", que emergem das recentes transformações nas relações entre capital, Estado e trabalhadores. Trata-se de riscos sociais decorrentes do aumento do desemprego, das novas exigências do mundo do trabalho e da tendência dominante de se afrouxarem os laços de filiação e solidariedade. Essa característica vem sendo enfatizada pelo sociólogo François Ewald, que argumenta que "O principal risco social de hoje não é o de se perder a renda, mais de não se ter um emprego para viver" (Ewald, 1999). O problema da empregabilidade vai se tornando peça-chave para análises dos defensores da sociedade de risco. 
Alguns autores, baseados nas teorias do operaísmo italiano, vão correlacionar essa relação risco-empregabilidade com o conceito, também foucaultiano, de governabilidade. Criticando e analisando a naturalização do conceito de risco social articulado à empregabilidade, vão argumentar que alguns mecanismos de individualização e gestão da vida se utilizam dessa relação riscos-empregabilidade para operarem seus comandos. Para eles as empresas, ao se utilizarem do conceito de risco social e de empregabilidade, vão se lançar como os principais arquitetos do comando social na contemporaneidade, buscando incluir sob a lógica do economicismo e do lucro a vida das pessoas como um todo, ou seja, a produção biopolítica. Assim, ao buscarem se tornar empregáveis, as pessoas estão se inserindo em mecanismos de controle que operam por uma autovigilância psicológica e comportamental afeita ao modo de produção atual. Como argumenta Marange (2001, p.163), “A vigilância psicossocial se faz, em efeito, sempre maior e insinuante, através da 'luta contra a violência', mas também diante de modelos de empregabilidade".

Douglas (1992) admite que a noção de risco tem um efeito também perverso quando se torna um uso político do conceito de perigo. Segundo ela, o uso tecnicista do risco pode encobrir ações políticas calcadas em preconceitos e racismo. Ou seja, quando se usa o conceito politicamente, “'risco' não significa [mais] uma estimativa geral de prováveis resultados, mas se torna uma arma de ataque à autoridade, [e] freqüentemente um slogan para aglutinar xenofobia" (Douglas, 1992, p. 39).

Aqui não temos a preocupação de debater os exageros ou acertos da denominação da sociedade de risco, mas simplesmente apontar como esse conceito vem sendo utilizado pelos mecanismos de poder, colocando em destaque a concepção de gestão das populações lançada por Castel em seu livro Gestão dos Riscos (1987). Nessa obra, o autor, claramente influenciado pelas últimas pesquisas de Foucault em torno do conceito de biopoder e biopolítica, vai descrever as transformações da gestão das populações que dão ênfase ao controle não mais das patologias e do tratamento dos sintomas, mas dos riscos de determinadas populações se desviarem, em algum momento de suas vidas, das normalidades esperadas para um cidadão médio.

A novidade trazida por Castel é que os mecanismos de gestão das populações se distanciam das práticas insulares características do período disciplinar e se adaptam muito mais às transformações colocadas em curso pelo pós-fordismo. Assim, prevenir é primeiro vigiar, quer dizer, se colocar em posição de antecipar a emergência de acontecimentos indesejáveis (doenças, anomalias, comportamentos de desvio, atos de delinqüência, etc.) no seio de populações estatísticas, assinaladas como portadoras de riscos. Mas o modo de vigilância promovido por essas políticas preventivas é totalmente novo em relação ao das técnicas disciplinares tradicionais. (Castel, 1987, p. 125-126).

É nesse sentido que o conceito de risco vai se tornando, cada vez mais, um instrumento de controle social no qual a ciência, os experts, são um dos principais elementos de produção de normas e a mídia o grande aparelho de controle. Analisando esse processo, é possível verificar como o risco à vida, assimilado intuitivamente pela multidão, vem a ser muito bem operado pelo capitalismo.

As pessoas, de uma maneira geral, pretendem viver com intensidade e saúde, para que cada momento de suas vidas seja transbordante de emoção, prazer, criatividade, amor. Atentar para o que coloca a vida em risco se torna uma tarefa de extrema importância: o cuidado com as crianças e suas brincadeiras perigosas, os ambientes de trabalho considerados insalubres; as más condições de vida das populações pobres; as lutas contra a poluição e as guerras, em particular a guerra nuclear. Enfim, uma série de medidas e reivindicações emergem, buscando minimizar os perigos que colocam a vida em xeque e reduzem a liberdade e a segurança das pessoas.

Ora, todo esse sentimento é muito bem trabalhado pelo capital. Assistimos constantemente a um bombardeamento de informações sobre a saúde, sobre os riscos da droga, sobre problemas de depressão e alimentação, sobre as formas de proteção das crianças, sobre o cuidado com a segurança no trabalho. A partir de uma série de reivindicações, que tem na vida e na saúde o seu foco principal, somos quase sufocados com campanhas, governamentais, midiáticas, de ONGs, as quais buscam atuar diretamente sobre o comportamento das pessoas, sempre em nome de um saber verdadeiro. Trata-se, pois, de uma tendência do capital de cada vez mais tornar científico e racionalizar o cotidiano. Diante desse contexto, a multidão afirma sua busca pela vida e pela promoção de um certo tipo de vida pelo poder, na qual as pessoas começam a vigiar e a controlar os seus hábitos, avaliando-os constantemente quanto aos perigos para o futuro e para o seu corpo, num controle intensamente individual e autovigilante. As reivindicações coletivas em prol da vida são intensificadas por uma série ilimitada de pequenos 
hábitos, atitudes e posicionamentos ético-políticos que devem ser assumidos individualmente ou, no máximo, familiarmente, pelas pessoas. Ora, com a idéia de que "cada um deve fazer a sua parte", o controle dos riscos vai assumindo importância fundamental como poder de autovigilância e como mecanismo de interferência nos hábitos das pessoas "pelo seu próprio bem", "pela sua própria vida". Além disso, trata-se de um poder que, apesar de operar em nome do todo, desmobiliza as atitudes coletivas contra os riscos, salvo aquelas levadas a cabo por organizações pontuais que buscam intervir exatamente nos hábitos das pessoas, ou, em outras palavras, exercer poder sobre os outros ${ }^{17}$.

Mas os efeitos dos riscos não param aí. A sociedade de normatização operava diretamente sobre cada corpo no presente, mas sempre amparado por uma fuga do tempo, projetada para um futuro no qual toda a intervenção do presente resultaria em um ótimo futuro. Ou seja, o corpo trabalhado no presente em cada instituição estaria, no futuro, pronto a exercer as atividades necessárias e benquistas pela sociedade. Tratava-se de uma proposta linear do tempo, apontada sempre para frente, pela qual, numa somatória de intervenções sobre o presente, chegar-se-ia a um futuro ideal em que os corpos estariam, como se supunha, prontos para produzir e obedecer.

A temporalidade moderna foi sendo modificada ao longo dos últimos anos. As certezas das projeções lineares positivistas foram recusadas ${ }^{18}$, bem como as reivindicações sociais contra o peso inevitável do futuro imutável $^{19}$. Na recusa dessa temporalidade, e pelos recentes mecanismos de poder que operam pelo risco, um dos efeitos sobre a temporalidade linear foi um esforço para dobrá-la sobre si mesma. Vaz mostra, por exemplo, que

O futuro cada vez mais depende da ação humana; esta, por sua vez, depende da expectativa que formamos sobre o que pode ser o futuro; a expectativa, por fim, depende das informações sobre o futuro. $\mathrm{O}$ decisivo

17 Hardt e Negri (2001) afirmam que as ONGs são as principais instituições de exercício do biopoder, caracterizando-se como novos instrumentos de poder.

18 O princípio da incerteza abriu um campo inestimável para o questionamento da ciência positivista, todavia os questionamentos filosóficos de Nietzsche, da psicanálise e até mesmo da lingüística saussereana foram igualmente importantes para que o estatuto da verdade absoluta da razão fosse sendo cada vez mais questionado enquanto lei universal.

19 Os movimentos de contracultura e a revolução feminista dos anos 60 foram fundamentais na recusa de um futuro anteriormente planejado. neste jogo estratégico é a capacidade de construir cenários considerando como uma informação sobre o futuro irá condicionar o modo de os outros simularem o futuro e, assim tomarem decisões: antecipar o modo como o outro antecipa e condicionar, através das informações, suas antecipações (Vaz, 1999, p. 101).

Vemos, portanto, que uma certa operação sobre o futuro é desencadeada. Enquanto pela norma a projeção para o futuro justificava a intervenção sobre o presente, o que o risco permite é modificar o presente por uma antecipação do futuro, que é previsto, a partir de operações estatísticas, pelas ações do presente. Aqui a função dos experts e da ciência é fundamental. Dessa maneira, a expectativa que criamos do futuro também está calcada no futuro que antecipamos. Assim, se uma certa antecipação do futuro nos indica algum risco para aquilo que não planejamos como o que deveria ser nosso futuro, devemos modificar aquilo que fazemos no presente para esperar que, no futuro, nosso presente seja melhor do que seria se não mudássemos nossos hábitos agora. Deixar de comer algo que nos dá prazer terá, portanto, um efeito reforçador, tendo-se em vista os benefícios que esperamos obter no futuro.

Esse mecanismo de poder, atrelado a uma cientificização dos hábitos de vida, aumenta ainda mais os efeitos de autovigilância e de autocontrole. A autovigilância e o autocontrole são disparados de modo tão intenso quanto eram disparados pelas instituições panópticas, mas de modo muito menos espacializado. Talvez seja por isso, podemos até arriscar, que o pânico seja um dos sintomas sociais mais característico da atualidade. A angústia desencadeada pelo objeto ameaçador "inexistente" ou "invisível" parece se tornar, nesse mecanismo, um efeito perverso de sua abstrata materialidade: em cada lugar um autocontrole, em cada gesto uma autovilgilância; tudo isso é acompanhado por uma ameaça insuportável de perda do vigor e da vida, levando as pessoas, em um surto de esgotamento de controle sobre si, acreditarem, apavoradamente, que estão morrendo, se esgotando, enlouquecendo, perdendo seu autocontrole e o comando sobre a sua própria vida. Essa hipótese, todavia, deve ser comprovada por outras análises mais detalhadas.

Seja como for, o que de mais importante sobressai dessa nova temporalidade histórica é o esforço ininterrupto dos mecanismos de poder e do capital de conseguirem planejar e comandar o impensável, o imprevisível, em uma palavra, o devir. Dessa maneira, a utilização do risco enquanto mecanismo de poder se 
encontra abertamente com a lógica da sociedade calcada no controle sobre a vida, sobre a mobilidade e a temporalidade intensiva (e não mais linear) da multidão; ou seja, sobre a tentativa ininterrupta do poder controlar o devir.

Sem pretender argumentar que o controle do risco é a única maneira encontrada para que o devir seja controlado, o que afirmamos nesse momento é que o estudo sobre a imprevisibilidade parece ser um dos instrumentos importantes que buscam tornar a singularidade sempre um elemento imediatamente assimilado pelo poder. Dessa maneira, o futuro utópico do modernismo, em que tudo no mundo estaria devidamente planejado e controlado pela razão "benevolente" humana, é abandonado em prol de uma temporalidade em que o futuro se dobra sobre o presente, buscando-se antever, pelas ações que ocorrem atualmente, as rupturas virtuais que podem emergir das práticas da multidão e, o poder, por meio dessas previsões, tenta incorporá-las, a partir da divulgação e da preparação dos riscos, levando as pessoas a agirem de acordo com aquilo que previram. Assim, buscase controlar o devir tanto pela antecipação que se faz dele, quanto pelo esforço para que ele não seja disparado em função dos comandos advindos da divulgação do risco.

Tem-se, então um mecanismo de poder que opera tanto pela produção de uma nova temporalidade quanto pela sugestão de autocontrole e autovigilância. Além disso, por sua imanência ao sistema - já que é um comando que emerge constantemente sem se referir a nenhuma instância trans-humana ${ }^{20}$-, o risco busca mapear e funcionar como pólo de atração das rupturas causadas pelo devir, numa tentativa de que tudo que é externo ao sistema seja, o mais brevemente possível, incorporado como parte dele, num esforço de produção de subjetividade e consumo incessante.

Ante o exposto acima, deixam-se abertas duas questões que servem muito bem de conclusão: em primeiro lugar, lembrando-se que o modelo de indivíduo erigido na modernidade estava intimamente atrelado aos mecanismos e técnicas de poder que operavam pela normatização do cotidiano, resta saber quais os efeitos que os novos mecanismos de poder, que operam pelo risco e pela cientificização do cotidiano, irão desencadear ou se relacionar com as novas concepções de indivíduos da atualidade principalmente com a idéia de que o indivíduo é

20 O risco é, por esse mecanismo, atrelado sempre ao comportamento de cada um, e, com raras exceções, se torna um problema das macroregulações dos Estados, das religiões, etc. multideterminado, pluriidentitário, complexo. Por outro lado, deve-se investigar mais atentamente quais as relações entre as patologias psíquicas mais comuns da atualidade - depressão e pânico - com essa estratégia de poder articulada ao risco. Por essas duas proposições evidencia-se que a questão do risco deve ser considerada com mais atenção pelos estudos da psicologia contemporânea.

\section{REFERÊNCIAS BIBLIOGRÁFICAS}

Bauman, Z. (1999). Globalização: as consequências humanas. Tradução Marcus Penchel. Rio de Janeiro: Jorge Zahar Ed. Pp. 85-110. Trabalho original publicado em 1998.

Beck, U. (2000). A sociedade global do risco. Disponível em: SWIF (http://lgxserver.uniba.it) Web italiano para a Filosofia Copyrigt 1997-1998. Tradução de Selvino José Assmann Florianópolis - UFSC - Depto. de Filosofia - julho de 2000, disponível em http://www.cfh.ufsc.br/ wfil/ulrich.htm

Castel, R. (1987). A gestão dos riscos: da antipsiquiatria à póspsicanálise. (C. Luz Trad.) Rio de Janeiro: Francisco Alves. pp. 100-179. (Trabalho publicado originalmente em 1981)

Cocco, G. (2000). Trabalho e cidadania: produção e direitos na era da globalização. São Paulo: Cortez.

Cocco, G. e Hosptein, G.(orgs.) (2002). As multidões e o Império: entre a globalização da guerra e a universalização dos direitos. Rio de Janeiro: DP\&A.

Coimbra, C. (2001). Operação Rio: o mito das classes perigosas. Rio de Janeiro/Niterói: Oficina do Autor/Intertexto.

Deleuze, G. (1992). Post-scriptum: sobre as sociedades de controle. Em Conversações. Tradução de Peter Pál Pelbart. Rio de Janeiro: Editora 34. pp. 219-226. Trabalho publicado originalmente em 1990.

Douglas, M. (1992). Risk and danger. In Risk and blame: essays in cultural theory. London, New York: Routledge. pp. 38-54.

Ewald, F. (1999). Un entretien avec François Ewald. Espace social européen. $\mathrm{n}^{\circ} 447,8-14$ de janeiro. Entrevista visitada no endereço

http://www.galeriesociale.com/ese/html/dos447enc03.html em março de 2002.

Foucault, M. (1979). O nascimento da medicina social. In Michel Foucault. Microfísica do poder. Rio de Janeiro: Graal. pp. 7998.

Foucault, M. (1987). Vigiar e punir. Tradução de Raquel Ramalhete. Petrópolis: Vozes. Trabalho original publicado em 1975.

Foucault, M. (1995). O sujeito e o poder. In Hubert Dreyfus e Paul Rabinow. Michel Foucault: uma Trajetória Filosófica. Rio de Janeiro: Forense. pp. 231-249. Trabalho publicado originalmente em 1982.

Foucault, M. (1999). Em defesa da sociedade: curso do Collège de France (1975-1976). Tradução de Maria Ermantina Galvão. São Paulo: Martins Fontes. Pp. 27-48. Trabalho original publicado em 1997.

Hardt, M. e Negri, T. (2001). Império. Tradução de Berilo Vargas. Rio de Janeiro: Record. Trabalho original publicado em 2000. 
Harvey, D. (1992). Condição pós-moderna. Tradução de Adail Ubirajara Sobral e Maria Stela Gonçalves. São Paulo: Edições Loyola. Pp. 115-184. Trabalho original publicado em 1989.

Layrargues, P. P. (2001). Razão e emoção em torno da tecnologia nuclear. Ciência hoje, 30 (175), set. 65-67.

Lazzarato, M. (2001). Le gouvernement par l'individualisation. In Multitudes, v. 4, mars. 153-162.

Lazzarato, M. e Negri, A. (2001). Trabalho imaterial: formas de vida e produção de subjetividade. Tradução de Mônica Jesus. Rio de Janeiro: DP\&A.

Marange, V. (2001). L'ethique du bouffon. In Multitudes, v. 4, mars. 163-170.

Marx, K. (1996). Para a crítica da economia política. In Os pensadores: MARX. Tradução de Edgar Malagodi. São Paulo: Editora Nova Cultural. Pp. 23-48. Trabalho original publicado em1903.

Piore, M. e Sabel, C. (1984). The new industrial divide. New York: Ed. Basic Books.
Pires, A. (2001) La rationalité pénale moderne, la société du risque et la juridicisation de l'opinion publique. In Sociologie et sociétés. Vol. 33, $\mathrm{n}^{\circ} 1 . \quad$ Disponível em: http://www.erudit.org/erudit/socsoc/v33n01/pires/pires.pdf em março de 2002.

Vaz, P. (1999). Corpo e risco. Fórum Media, Viseu, v. 1, n. 1, p. 101-111. Disponível em: www.angelfire.com/mb/oencantador/paulovaz/INDEX. html em setembro de 2001. 